\title{
A linguagem em condições diferenciadas: conhecendo e desvendando os seus distúrbios*
}

Language in unusual conditions: speech disorders

Ana Paula da Silva Passos'

\section{Introdução}

O Programa Linguagem em Condições Diferenciadas (PLCD) foi fundado com o propósito de estudar distúrbios que afetam a linguagem. Entende-se por condições diferenciadas as situações em que a linguagem se encontra de algum modo alterada em relação ao que as pessoas consideram como 'padrão normal' (linguagem falada por indivíduos em boas condições de saúde). O PLCD é um programa de extensão que visa oferecer esclarecimento à população sobre dois distúrbios relacionados à linguagem: Afasias e DEL. No momento, o Programa é coordenado por um professor doutor em Linguística do Instituto de Letras da Universidade do Estado do Rio de Janeiro (UERJ), contando ainda com a colaboração de uma professora doutora em Linguística, também do Instituto de Letras, além de três bolsistas de extensão, um de iniciação científica, um voluntário e um fonoaudiólogo.

\section{História}

Ao mencionar o Programa Linguagem em Condições Diferenciadas, devemos nos remeter à sua história que começou em 1992, na I UERJ sem muros. A professora Eulália Fernandes do Instituto de Letras, com a colaboração da então assessora da Reitoria professora Maria Theresinha do Prado Valladares, criaram um projeto de extensão voltado para a comunidade surda, o Projeto Surdez. Inicialmente, a professora Eulália Fernandes desenvolveu um projeto que visava atender a comunidade surda no que se refere à prevenção de HIV/ AIDS, utilizando a Língua de Sinais e recursos educacionais para desenvolver material didático com essa finalidade. No entan-

\section{Resumo}

Este relato busca apresentar as atividades realizadas pelos projetos de extensão que constituem o Programa Linguagem em Condições Diferenciadas (PLCD), que têm como foco a afasia, o DEL (Déficit Específico da Linguagem) e a surdez. Os projetos do PLCD lidam diretamente com distúrbios que podem afetar a compreensão e a produção da fala (ou no caso da surdez, mais especificamente sobre as dificuldades dessa população para o uso da língua portuguesa escrita). O objetivo dos projetos é fazer um trabalho de divulgação, fornecendo informação à população em geral sobre estes distúrbios que são pouco conhecidos, além de fornecer subsídios, por meio de testes psicolinguísticos, para aprimoramento das técnicas fonoaudiológicas utilizadas no tratamento dos pacientes com estes distúrbios. Como um programa que abriga projetos de extensão, o PLCD vem reforçar a importância do conhecimento destes distúrbios da linguagem por profissionais da saúde e da educação para encaminhamento de possíveis portadores para tratamento fonoaudiológico. O presente trabalho visa oferecer um panorama das ações do PLCD e seus respectivos projetos relacionados à tríade extensão, ensino e pesquisa e seu impacto em cada um desses campos.

Palavras-chaves: Afasias; DEL; Surdez; Comprometimentos da Linguagem

Área Temática: Direitos Humanos e Justiça Linha de Extensão: Pessoas com Deficiências, Incapacidades e Necessidades Especiais 
to, outros projetos e atividades foram elaborados, constituindo, então, um conglomerado de projetos, um programa, denominado Programa Surdez.

Em 2003, a professora Eulália Fernandes se aposentou e entregou a coordenação do Programa Surdez para o Departamento de Estudos da Linguagem do Instituto de Letras da UERJ. Em 2007, um dos professores do Departamento assumiu, oficialmente, a coordenação do Programa Surdez. No entanto, devido à área de atuação do professor, o Programa sofreu uma expansão e suas atividades se estenderam para o campo da Afasiologia e, mais recentemente, outro distúrbio da linguagem também passou a fazer parte dos estudos e atividades do Programa, o DEL (Déficit Específico da Linguagem). Com essa expansão, o Programa Surdez passou, então, a se chamar Programa Linguagem em Condições Diferenciadas (PLCD).

Apesar da mudança do nome, o PLCD continua a divulgar os legados do Programa Surdez como as cartilhas educativas que foram elaboradas a fim de esclarecer e fornecer informação à população sobre a comunidade surda: "Desfazendo Mitos e Mentiras sobre as línguas de sinais" e "Uma língua que se fala com as mãos? A gente explica!”.

\section{Projetos}

O PLCD abriga, atualmente, dois projetos: o Projeto Linguagem em Circunstâncias Excepcionais estuda as afasias - lesões no cérebro que levam a uma fala desordenada que depende de tratamento fonoaudiológico para reabilitação; e o Projeto DEL (Déficit Específico da Linguagem): conhecendo populações em condições diferenciadas de aquisição da língua, que se volta para um comprometimento que afeta a estrutura da língua na fase de aquisição, podendo acarretar dificuldades no processamento de enunciados linguísticos tanto na compreensão quanto na produção da linguagem.

\section{A importância da Interdisciplinaridade}

O arcabouço teórico e prático que subjaz aos projetos do PLCD conta com a integração de três áreas: a Linguística, designada como ciência da linguagem, oferece o arcabouço teórico para entendermos como funciona a linguagem nos seres humanos; a Psicolinguística que, tomando por base as teorias linguísticas, e tendo como foco as operações mentais que estariam envolvidas no processo de compreensão e produção da linguagem, propõe modelos de processamento da linguagem e adota uma metodologia criteriosa de testagem que muito podem auxiliar no diagnóstico das afasias e do DEL; e, finalmente, a Fonoaudiologia se encarrega de definir o tratamento mais adequado para o déficit que o paciente apresenta. Portanto, assume-se a necessidade de uma interdisciplinaridade no tratamento de alterações que afetam a linguagem.

\section{Projeto Linguagem em Circunstâncias Excepcionais}

O Projeto Linguagem em Circunstâncias Excepcionais tem como meta divulgar informações sobre afasias. Afasias são eventos neurológicos cuja característica principal é uma alteração específica na linguagem, tanto em sua produção quanto em sua compreensão ${ }^{1}$. Para atingir esse objetivo, realiza-se acompanhamento e atendimento de afásicos, elaborando atividades e materiais de divulgação.

Através do Projeto Linguagem em Circunstâncias Excepcionais, foram criadas cartilhas para fornecer informações à população e ao paciente sobre o distúrbio. A cartilha "Falando sobre afasia, entendendo o afásico", fornece informações sobre o que é afasia, como e onde tratar, e ainda, o papel da família na recuperação do paciente.

O Projeto Linguagem em Circunstâncias Excepcionais tem parceria com a fonoaudióloga Solange Iglesias de Lima do Centro de Recuperação de Pacientes Afásicos (CRPA) do Centro de Saúde Veiga de Almeida para desenvolver testes e conduzir o tratamento dos afásicos. Os bolsistas de extensão, por vezes, acompanham o tratamento de alguns pacientes para complementar as atividades do projeto e, consequentemente, as atividades de divulgação do Programa.

Em 2009, as atividades do projeto resultaram na organização do livro Pesquisa e Material Desenvolvidos com Base em Critérios Lingüisticos para a Prática Fonoaudiológica nas Afasias com o objetivo de auxiliar os profissionais da área de fonoaudiologia com dados que possam contribuir para o tratamento dos pacientes ${ }^{2}$.

No ano de 2010, o Projeto Linguagem em Circunstâncias Excepcionais se propôs a tra- 
tar de um tema que fez parte do livro produzido pelo Programa Linguagem em Condições Diferenciadas: trata-se da habilidade de reter em um curto período de tempo palavras e sons para que possam ser utilizados na repetição e na compreensão da linguagem. Assim, por exemplo, frases muito complexas podem não ser entendidas pelo afásico porque estes não conseguem manter na memória de trabalho verbal as palavras iniciais e fazer conexão com as finais. $\mathrm{O}$ teste de repetição de não-palavras - palavras inventadas - é o mais indicado para medir essa habilidade. Em 2010, o teste foi reduzido e reelaborado; procedeu-se a sua aplicação em indivíduos sem lesão cerebral e posteriormente em indivíduos afásicos. Constatou-se que todos têm problemas em manter informação verbal por um curto período de tempo, sendo essa dificuldade mais acentuada nos afásicos. A ideia de que se falássemos com os afásicos pausadamente, silabando as palavras ("te-le-vi-são") é difundida no senso comum; portanto, a segunda etapa do projeto investigou, através da aplicação do teste pela bolsista do projeto, se essa ideia melhoraria o desempenho dos afásicos. Não foi constatada uma melhora significativa no desempenho, o que significa que a ideia do senso comum não tem respaldo científico. Esse resultado foi bastante importante uma vez que mostrou que uma pesquisa pode trazer contribuições para a prática fonoaudiológica e para desfazer mitos na vida cotidiana dos afásicos ${ }^{3,4}$.

\section{Projeto DEL (Déficit Específico da Linguagem): conhecendo populações em condições diferenciadas de aquisição da língua}

O Projeto DEL (Déficit Específico da Linguagem): conhecendo populações em condições diferenciadas de aquisição de língua se volta para um déficit que perturba o processo de aquisição da linguagem e que, se não for tratado a tempo, pode perdurar até a fase adulta ${ }^{5,6,7,8}$. Um dos principais objetivos do Projeto de Extensão é a divulgação de informações para a população sobre esse distúrbio, que tem sido realizada com o apoio de uma cartilha desenvolvida no Projeto e distribuída em clínicas e eventos, além de se promover visitas às salas de aula do Instituto de Letras. Esse Projeto tem parceria com o Laboratório de Psicolinguística e Aquisição da Linguagem (LAPAL) da PUC-Rio, coordenado por Letícia M. Sicuro
Corrêa, que vem desenvolvendo os vários estudos sobre DEL no Rio de Janeiro ${ }^{9,10,11,12,13}$. Nessa empreitada, foi elaborada uma bateria de testes psicolinguísticos denominada MABILIN ${ }^{14}$ a fim de diagnosticar possíveis portadores de DEL. A parceria entre as universidades concentrou-se, nos anos de 2009 e 2010, na aplicação dessa bateria de testes em crianças da rede pública de ensino. Foram contempladas 288 crianças de 7 a 10 anos de idade de duas escolas: Escola Municipal Artur Ramos e Escola Municipal Oscar Tenório, tendo sido aplicada a bateria de testes por bolsistas do PLCD e do LAPAL com acompanhamento e orientação de fonoaudiólogos e professores.

Também em 2010, iniciou-se um estudo de caso com algumas crianças das 288 mencionadas acima, a fim de realizar atividades linguísticas com as mesmas, isto é, atividades lúdicas que façam com que a criança tenha de produzir ou compreender sentenças consideradas complexas para crianças portadoras de DEL (sentenças passivas, relativas e interrogativas QU-). A atuação dos bolsistas do Projeto nessas atividades colabora para a aproximação entre academia e a comunidade externa.

\section{Projeto Linguagem em Condições Diferenciadas}

O projeto que recebe o mesmo nome do Programa tem como objetivo a organização das informações pertinentes aos outros dois projetos, a fim de divulgar essas informações de maneira clara e objetiva para a população. Uma das características deste projeto é não ter um público-alvo fixo: toda e qualquer pessoa interessada ou relacionada a condições diferenciadas de linguagem (familiares, amigos, profissionais) é considerada como um público para o projeto, pois todos poderão, eventualmente, ter contato com algum portador de quaisquer desses distúrbios, tanto a população acadêmica, quanto a população extra-acadêmica, os professores e profissionais de educação e profissionais da área de saúde. Sendo assim, o bolsista deste projeto deve estar ciente e ativo em todas as atividades do Programa.

A grande quantidade de informações pertinentes aos distúrbios da linguagem e o avanço tecnológico presente em nossa atual sociedade fizeram com que a equipe do PLCD refletisse sobre uma maneira adequada de passar esses dados para 
a população. De modo a atingir um público maior com a ajuda da internet, foi criado em agosto de 2010 o site do PLCD (www.plcduerj.com.br), com informações sobre estes distúrbios no que se refere a ensino, extensão e pesquisa.

\section{Impactos em ensino e pesquisa}

Além da atuação como programa de extensão, o PLCD também tem impacto direto na formação dos alunos de graduação em Letras. Através da disciplina Linguística, os alunos podem ser apresentados a estas condições diferenciadas de linguagem, fazendo com que tomem consciência da existência dos distúrbios. O interesse pelo assunto aproxima os alunos do Programa, sendo comum os bolsistas de extensão que se envolvem nas atividades do Programa continuarem seus estudos de pós-graduação nesta área. O PLCD serve como uma ponte entre extensão e pesquisa, já tendo sido defendidas três teses de mestrado ${ }^{15,16,17} \mathrm{com}$ uma quarta em andamento, todas relacionadas às condições diferenciadas de linguagem tratadas pelos projetos do Programa.

O impacto dos estudos de linguagem em condições diferenciadas e o empenho da equipe têm trazido resultados positivos, que evidenciam o forte aspecto formador do Programa, como a premiação da bolsista do Projeto Linguagem em Condições Diferenciadas no I Prêmio de Extensão Professora Maria Theresinha do Prado Valladares, além de menção honrosa concedida a outra bolsista do Programa, pelo seu desempenho junto ao Projeto DEL.

\section{Perspectivas para 2011}

Para 2011, encontra-se em fase de implantação um novo projeto para o PLCD que retoma as atividades relacionadas à comunidade surda, denominado o Projeto Comunicação e Expressão em Língua Portuguesa para Surdos: o Papel do Artigo. Além disso, com o Projeto Linguagem em Condições Excepcionais pretende-se expandir a pesquisa realizada em 2010, levando informações para setores da sociedade que possam se interessar ou que precisem ser informados a respeito desse assunto. Com o Projeto DEL, planeja-se o aprimoramento das atividades em desenvolvimento com a parceria do LAPAL da PUC-Rio, no sentido de se dar continuidade à avaliação das crianças da rede pública de ensino. Em 2011, o site do PLCD também receberá atualizações acerca das informações, pesquisas e atividades do Programa, além de elaborar novas maneiras de divulgar informação para a população, de modo a atingir um público maior.

Como um programa de extensão, o PLCD procura oferecer informações objetivas e claras para a população, além de fornecer informações atualizadas para os estudiosos dos distúrbios citados. Além disso, contribui para a integração de três áreas - Linguística, Psicolinguística e Fonoaudiologia - visando o aprimoramento do atendimento dos pacientes.

\section{Referências}

1. JAKUBOVICZ, R.; CUPELLO, R., Introdução à Afasia - Elementos para diagnóstico e terapia. $6^{a}$ edição, RJ, Revinter, 1996.

2. LIMA, R.J; LIMA, S.I(org); Pesquisa e Material Desenvolvidos com Base em Critérios Lingüísticos para a Prática Fonoaudiológica das Afasias; CD-ROM, edição Universidade Veiga de Almeida, RJ, 2009.

3. MANSUR, L.; RADANOVIC, M. Neurolingüística: princípios para a prática clínica. Edições Inteligentes : São Paulo. 2001.

4. ORTIZ, K.Z. Avaliação e terapia dos distúrbios neurológicos da linguagem e fala. In: LOPES FILHO, O. Tratado de Fonoaudiologia. SP: Roca, 1997.

5. FRIEDMANN, N; NOVOGRODSKY, R. Subtypes of SLI: SySLI, PhoSLI, LeSLI, and PraSLI. In: A. Gavarró, \& M. João Freitas (Eds.), Language acquisition and development (pp. 205-217). Cambridge Scholars Press/CSP. Newcastle UK. 2008.

6. LEONARD, L. Children with specific language impairment. Cambridge, MA: MIT Press. 1998.

7. BEFI-LOPES, D.M.; BENTO, A.C.P.; PERISSINOTO, J. Narração de histórias por crianças com distúrbio específico de linguagem. Pró-Fono, Barueri (SP), v. 20, p. 93-98, 2008.

8. PUGLISI, M.L.; BEFI-LOPES, D.M. \& TAKIUCHI, N. Utilização e compreensão de preposições por crianças com Distúrbio Específico da Linguagem. Pró-fono, Barueri (SP), v. 17, n. 3, p. 331-344, 2005

9. AUGUSTO, M.R.A. A estruturação sintática de construções que apresentam dificuldades para o portador de DEL. Relatório de pesquisa apresentado ao CNPq. Rio de Janeiro. 2004.

10. CORREAA, L.M.S. Possíveis diálogos entre Teoria Lingüística e Psicolingüística: questões de processamento, aquisição e do Déficit Específico da linguagem. In: N. MIRANDA; M. C.L. NAME (Orgs.). Lingüística e Cognição, Juiz de Fora: Editora da EFJF. 2005.

11. CORRÊA, L.M.S. \& AUGUSTO, M.R.A. Possible loci of SLI from a both linguistic and psycholinguistic perspective. Lingua. Elsevier. Amsterdam The Netherlands. Volume 121, Issue 3, Pages 476-486. 2011. Disponível em: http:// dx.doi.org/10.1016/j.lingua.2010.10.011, 2010. 
12. HAEUSLER, O. C. F. A Estrutura Argumental de Verbos na Produção Eliciada de Crianças com Queixas de Linguagem e Manifestações do Déficit Especificamente Lingüístico (DEL) no Português do Brasil. Dissertação (Mestrado em Letras). Pontifícia Universidade Católica do Rio de Janeiro, PUC-RJ, Rio de Janeiro. 2005.

13. SILVEIRA, M. S. da. O déficit especificamente Lingüístico (DEL) e uma avaliação preliminar de sua manifestação em crianças falantes de português. Dissertação (Mestrado em Letras). Pontifícia Universidade Católica do Rio de Janeiro, Rio de Janeiro, 2002.

14. CORRÊA, L.M.S. Relações entre DEL (Déficit Específico da Linguagem) e problemas de linguagem no quadro do DAp (Dificuldades de Aprendizagem): módulo sintático, interface gramática-pragmática e caminhos para intervenção. Projeto FAPERJ (Cientistas do Estado) (E26/152.270/2008), Rio de Janeiro. 2008.

15. AQUINO, V. A influência da linguagem para o raciocínio de crenças falsas em Teoria da Mente: uma análise em pacientes afásicos agramáticos. Dissertação (Mestrado em Letras). Instituto de Letras, Universidade do Estado do Rio de Janeiro, Rio de Janeiro, 2010.

16. FORSTER, R. Morfologia flexional, sentenças complexas e não-canônicas na produção de afásicos não-fluentes. Dissertação (Mestrado em Letras). Instituto de Letras, Universidade do Estado do Rio de Janeiro, Rio de Janeiro, 2008.

17. VILLARINHO, C. A seleção de pacientes em estudos lingüísticos sobre o agramatismo e a afasia de Broca: problemas e soluções para o debate sobre estudos de caso e de grupo. Dissertação (Mestrado em Letras). Instituto de Letras, Universidade do Estado do Rio de Janeiro, Rio de Janeiro, 2008.

\section{Abstract}

This report presents the activities carried out in the Projects which make up PLCD - Language in Unusual Conditions Program (Programa Linguagem em Condições Diferenciadas). The projects focus on aphasia, SLI (Specific Language Impairment) and deafness. The main aim of this report is to provide information about these deficits (in the case of deafness, to emphasize the importance of sign language in the development of deaf children and to inform about the difficulties Portuguese language imposes on written use). Theoretically, the projects in the PLCD discuss different aspects of these disorders from a linguistic/psycholinguistic point of view, contributing for intervention conducted by speech therapists. In this report we present the impact of the actions taken by the PLCD for community affairs and culture, education and research.

Keywords: Aphasia; SLI; Deafness; Language Deficit 